Fall 2009

\title{
Reconfiguring the borderlands of identity: Preparing social justice educators
}

Anita E. Fernandez

Follow this and additional works at: https://digitalscholarship.unlv.edu/jpme

\section{Repository Citation}

Fernandez, Anita E. (2009) "Reconfiguring the borderlands of identity: Preparing social justice educators," Journal of Praxis in Multicultural Education: Vol. 4: No. 1, Article 1.

DOI: $10.9741 / 2161-2978.1000$

Available at: https://digitalscholarship.unlv.edu/jpme/vol4/iss1/1

This Article is protected by copyright and/or related rights. It has been brought to you by Digital Scholarship@UNLV with permission from the rights-holder(s). You are free to use this Article in any way that is permitted by the copyright and related rights legislation that applies to your use. For other uses you need to obtain permission from the rights-holder(s) directly, unless additional rights are indicated by a Creative Commons license in the record and/ or on the work itself.

This Article has been accepted for inclusion in Journal of Praxis in Multicultural Education by an authorized administrator of Digital Scholarship@UNLV. For more information, please contact digitalscholarship@unlv.edu. 


\title{
Reconfiguring the Borderlands of Identity: Preparing Social Justice Educators
}

\begin{abstract}
Anita E. Fernández
This article offers multiple pedagogical approaches for mobilizing Gloria Anzaldúa's metaphor of borderlands to prepare social justice educators to address issues of justice and equity in increasingly diverse classroom settings. It describes an experiential course in multicultural education, including innovative processes through which Education students analyze the borderlands of identity, society, and geography through critical self-analysis, fieldwork, and social action. By investigating the intersectionality of social justice issues and the social construction of identity, students attempt to transform the borders of their own identities and engage in action projects to begin a process of bridging the edges of cultural inequity.
\end{abstract}

Gloria Anzaldúa (1999) claims that we are always on the borderlands—between people, between races, between genders, and between classes. She views this intersectionality as fundamental to understanding our own identities. Her insight challenges atomistic understandings of personhood by providing a useful metaphor for analyzing individuals in relation to one another, to interconnected communities, and to systems of power and privilege. As a teacher educator, I have witnessed the profound impact of future teachers investigating the many aspects of their identities and analyzing how these multiple dimensions relate to systemic social issues. This process is especially relevant to my students' relationships to their future students. As the K-12 population in the U.S. becomes increasingly diverse and incoming teachers continue to be predominantly white and middle class (Cochran-Smith, 2004), there is a sense of urgency to prepare socially just, culturally responsive (Gay, 2000) teachers. One way to address this challenge is to require Education students to delve deeply into their own backgrounds, beliefs, and biases as well as to investigate the intersectionality of social justice issues. During a course on race, power, and identity, my Education students explored and analyzed borderlands of identity, society, and geography through intensive self exploration, critical social theory, and experiential assignments that asked them to traverse the boundaries they were learning to recognize and articulate. Because of our college's proximity to la frontera, the U.S./Mexico border, and due to the segregation in our own

Anita E. Fernández is a professor of Education as well as the Education Program Coordinator at Prescott College. Her areas of research and interest include social justice education and multicultural education.

community between Latinos and Anglos, the concept of borders and borderlands emerged as an acute description and simultaneously as an enabling metaphor for delving into the intersectionality of social justice issues and identity analysis. Additionally, the border became a locale for fieldwork and an opportunity for social action.

Crossing the street from the barrio, where many of my college students find housing, to our small, predominantly white liberal arts college began as a border-crossing practice that was largely invisible and meaningless to many of my students. In the process of exploring the geographic and metaphorical borders that Anzaldúa articulates, the act of crossing this street has become symbolic of crossing a borderland, "a vague and undetermined place created by the emotional residue of an unnatural boundary" (Anzaldúa, 1999, p.25). On one side of the street, a group of Latino migrant workers wait daily on the corner in the hopes of landing a day job, and on the other side of the street college students enter the world of higher education, environmental sustainability, opportunity, and privilege. Our street has in a sense become a continuation of la frontera, 200 miles to the south of us, a border which many of the day laborers have crossed themselves for an opportunity to make a living wage for their families. Over the course of a semester, my students investigated the complex issues impacting the day laborers as well as how students' own identities intertwine with the day laborers' experiences. In an attempt to bring light to many of the social justice issues we studied, fieldwork was conducted along the border fence as well as at an intercultural, bilingual border school steeped in indigenous Mexican culture. Finally, students participated in a social action project working as English as a Second Language tutors for Spanish speakers and/or participating in social justice work with local groups advocating for the rights of migrant workers. By engaging in this kind of practice, future teachers, most of whom are white and middle class, can potentially become more effective educators and supporters of all children and thus contribute to the reconfiguration of racial borderlands in education.

\section{Intersectionality of Our Own Identities}


Our study of borders began with ourselves, with the socially constructed lines we maintain between and within the many aspects of our identities. We investigated how whiteness overlaps with gender and how class weaves through all of the multiple pieces of who we are and how we move through the world. Because of their commitment to becoming equitable and compassionate social justice educators, these students courageously threw themselves into this work that is often painful and confusing. They took on the challenge of looking at issues of race, power, and privilege in the eye and "owning up to the venom" (Kingsolver, 1995).

An integral piece of encouraging students to earnestly pursue this work is engaging in the process of identity analysis with them rather than telling them how to dig in themselves. From the start of our course, I am open and honest with my students about how I identify and how my identity has changed over time-modeling the fluidity of who we are at different times, in different spaces. I explain to them that I did not always identify as Latina because the world did not reflect that specific identity back to me. My upper-middle class family lived internationally for the first twelve years of my life; therefore the messages I received were usually filled with acceptance and an abundance of privilege. It was not until at the age of twelve, when I moved to the U.S., that I began to receive a constant jabbing, a reminder that I was different than my New England peers, simply because of my name and my father's ancestry. Because class often overrides race and ethnicity in terms of privilege, I managed to move successfully through the taunts and name-calling with little negative impact on my opportunities bestowed by class privilege. Later in life, when I began to teach high school students, most of who were Latino, I was struck by the connection the Latino students had to me even though I did not identify as Latina. I was an instant ally for them in a system of racial, linguistic, and class discrimination, because I spoke their language and carried a name they could identify. From that point on, I outwardly claimed my Latina identity as a direct way to advocate for my Latin American students who so often were invisible to the counselors, teachers, and administrators in public schools. I tell my current students that the privilege I experience today, actually exceeds their white, middle-class privilege, because I can move comfortably in two worlds. I can be accepted as white, most of the time, and can navigate through the Latina/o culture as well. I have both the insider and outsider perspective giving me access to two different worlds and ways of being.

The tendency, mine as well as other multicultural educators, when teaching about social justice issues is to divide a course up into the various topics such as race, gender, sexual orientation, etc. and cover a topic every week or two as a way to ensure that all the "isms" are discussed. In an attempt to emphasize the interconnectedness of these issues, specifically as they relate to our own identities, my students were required to tape record an interview with themselves on a variety of topics surrounding social justice issues before our course began. By replicating this activity, which Beverly Tatum (1992) conducted in a Psychology of Racism class, the interviews served as a point of departure, which would be visited again at the end of our course and analyzed for growth over the semester. Students were encouraged to find a quiet time to answer a set of questions (Appendix A) as honestly as possible and tape-record their answers. They were assured that no one, including myself, would listen to their tapes, although I would hang on to them for safe-keeping. Some interview questions dealt with specific identity pieces, "How do you see yourself today if you had to identify racially?" while others were more general, "Do you believe that everyone in the U.S. can be successful if they work hard enough?" At the end of our course, students analyzed their interviews using Helms' (1990) racial identity theory as well as Howard's (2006) themes of "the luxury of ignorance," "the legacy of privilege," and "the assumption of rightness" to frame their analyses. Because racial identity theories only take race into consideration, students drew on multiple categories of difference simultaneously to explore the fluid borders of their identities.

Upon reflection of their taped interviews, most students found themselves more informed by the end of the course, yet with an abundance of work to be done. Race, specifically whiteness, was an area all the students focused on with regards to their own identity as they grappled with the notion that race is a social construct yet it determines so much about how we live our lives, what opportunities we are afforded and how the world views us. Once there was a solid understanding of privilege and power as connected to race, students then began to investigate how they, as white educators, could begin to have an impact on an oppressive system:

At the beginning of this course, I felt fairly lost concerning my own identity and how that would influence my role as an educator, though I knew what morals I wanted to work toward. I didn't know, however, how to do social justice work or ally work as a white person and not continue to support an oppressive system. I felt an inherent paradox being a white person trying to do this work. I now understand that cultivating a positive white identity and being in the autonomy stage [Helms, 1990] is the key to working for social justice without continuing the same dominance paradigm. 
The autonomy stage is where, according to Helms, race is no longer a threat to white people. By acknowledging systemic racism, this student has in fact reached the autonomy stage, as she has realized she now can, and must, engage in social justice work to resist this system of oppression. This borderlands process of self-inquiry has made it possible for her to be both white and anti-racist - to move beyond the socially constructed borders of our identities.

Along with a desire to cultivate a positive racial identity, the intersectionality of our identities proved to be a challenge for students as they sought a concrete definition of who they are. The intersection of race and gender was prominent in our discussions as well as in their analyses of their tapes, yet the assumptions around class were the most alarming to me as well as to themselves in retrospect.

In my family...poor equals lazy. It was clear to me in my place of upbringing, where segregation is still permeated via housing lines, that black people were the poor folks, and white people were the wealthier. Therefore, in my eyes, black people were lazy and less, and white people were the successful norm. It's amazing what kids gather from the unspoken.

As students unpacked their assumptions of rightness, where the "dominant groups tend to claim truth as their private domain" (Howard, 2006, p.54), and their luxury of ignorance, the metaphor of borders began to surface. The borders of their religion sometimes overshadowed their whiteness or the borders of their English language proficiency overrode their class. One student reflected,

...I started to wonder, where was my Whiteness growing up? I couldn't find it. I listened to my tape and all I heard was Jewish, and I wondered where the white had gone. It occurred to me that maybe my whiteness was buried in the Jewish.... maybe it was taboo and no one wanted to talk about the white part, so it lived in the Jewish.

She would go on to name this as an example of the luxury of ignorance, which often reinforces the assumption of rightness. By emphasizing our multiple identities, the intersectionality of who we are, students were given permission to see themselves through multiple lenses and to acknowledge how those views influence their own experiences as well as the experiences of those around them. This student was able to explore the borderlands of her identity as a white Jewish woman and eventually own up to the whiteness and reach for the autonomy stage. This process of reconfiguring the borderlands of who she is, allowed this student to emerge with a positive white identity to support her Jewish identity.

\section{Intersectionality of Social Justice Issues}

Early in the semester, my teaching assistant, the only student of color in the class, shared his experience of "crossing the street" that day. He explained that as a person of color who had been adopted by a white family, he never viewed himself as the "other" until he moved to the Southwest where he clearly looked like an immigrant-his Salvadoran looks and his attire matched those of the day laborers who stood across the street. His experience that day had been one of shame, frustration, and privilege in his words. He was walking past the men on the corner when he realized that they thought he was "one of them," and when they addressed him, he could not respond, as he had never learned Spanish. He felt ashamed and guilty at the loss of his heritage, and as he left the men behind, crossing the street to the college, he felt "embarrassed of [his] privilege."

My teaching assistant's reflection on crossing the street brought to light the complexity of our identities and also the intersectionality of social justice issues. The many issues affecting the day laborers were the topics we were discussing in class in order to have a firmer understanding of our future students and the systemic issues that affect children and their families. The inherent racism against immigrants, particularly those from Latin America, could not be separated from the issue of language when considering the experiences of migrant workers. Our privilege and power could not be fully understood until we investigated how it impacts immigrants, especially non-native English speakers. The systemic inequities around class overlapped with the pathways to citizenship in the U.S. Over time, we began to realize that all of these issues edged on each other's boundaries, on their borders, and in order for us to begin to transform these edges and inequities, we needed to step out of our small classroom and begin to "transform the contradictions of borders into something else more humane" (Chavez-Chavez, R. 2007. Interview by David Rutledge. Online video recording. July 7. New Mexico State University). Once we began to recognize, analyze, and, as my teaching assistant's distressing encounter demonstrates, experience the ways that socially constructed identity borders shape us and the ways that our everyday actions unconsciously reinforce borders of social inequality, we were ready to explore the ways that we have the power to intentionally shape those borders. Because education is 
both social and political (Freire, 1970), engaging with our immediate community, both across borders, and face-toface, was imperative for these future teachers to begin this transformation.

\section{Social Action}

Because our college emphasizes experiential, place-based education, the emphasis on fieldwork provided a way for students to participate in this face-to-face engagement with their communities rather than staying in our classroom. As a part of this particular course, students were required to familiarize themselves with and then participate in a social action project attempting to work with a population different from themselves and working for positive social change. Toward this process of familiarization, a group-based experiential component of the course was a trip to the border where we were able to see how lives are impacted by the social justice issues we were studying. We spent time on both sides of the border fence where we talked to children, border patrol, indigenous leaders, teachers, and parents in an attempt to hear a variety of voices and perspectives along the border. Hearing about the impact of the border fence on all these stakeholders was a way to bring the notion of the borderlands to life, the places where intersectionalities occur.

On a visit to Mexicayotl Academy, an intercultural K-8 bilingual school, we were introduced to the school's philosophy based in the essence and heart of the Mexican people. The school's director, Baltazar Garcia, talked in depth with us about the three-part mission of the school: to know, to care, and to act. This mission resonated with my students as we too had been focusing on these three areas. Baltazar emphasized that in order for his children to be successful, $82 \%$ of who were English language learners, they first needed to know themselvessimilarly to my students trying to know themselves-and where they came from. Secondly, they needed to care about others and devote themselves to understanding the world around them. Finally, the students were encouraged to actto be positive role models in their community and act in a way that transforms the world around them. This mission and emphasis on critical self-exploration resonated with my students as they could see the value in knowing, caring, and acting upon the world around them. Clearly, the difference between my students' experience of self-exploration and the students' at Mexicaytol is that my students' lives would not necessarily be negatively impacted if they chose not to engage in this work. The Mexicaytol students' lives certainly would be influenced by becoming bilingual and bicultural while maintaining a deep sense of who they are and where they come from. Witnessing this model of education and of what "could be" was life changing for my students. The opportunity to hear stories from children about life on the border gave us an authentic testimonio, or bearing witness, of what we had been studying in our small classroom and discussing amongst ourselves. To see my students engage with different groups along the border and ask critical yet compassionate questions was incredibly rewarding and reaffirming of this kind of work.

Before and after our fieldwork along the border, my students were engaged in weekly or biweekly social action projects. The two projects that students chose from were either tutoring Spanish speakers (mostly migrant workers) in English or working with different organizations advocating for immigrant rights. One concern I had in assigning this project was that it might perpetuate the "missionary zeal" often produced by community service work. I wanted to attempt to eradicate the notion that white folks have all the answers for people of color. Missionary zeal comes from the atomistic understanding of identity that recognizes that some groups of people suffer more than others and could use some help. In contrast, the borderlands understanding of identity allows people to understand the interdependence of power and privilege and so to grasp that middle class white people making decisions for poor people of color is actually part of the process of maintaining social inequality, hence, ally groups with more power must learn to share their privilege in a way that challenges those boundaries by following, rather than leading social change projects in less empowered communities.

Because the major areas of study for this course were race, power, and identity, students' reflections on their action projects centered on these topics. This proved to be an emotional as well as intellectual learning process. The reality of working with individuals from the Latino community in our town was not only new to the students but also intimidating and uncomfortable. The history of segregation in this town along with the current anti-immigrant sentiment in the U.S., created a discomfort for my students that surprised them.

The first time I went to class [ESL] I felt myself 'othering' the Latinos...I was hesitant to look them in the eyes or even just say hello to them. I came in there with an assumption of who these people were, that they were all 'illegal' immigrants... while some of my assumptions were right, they were steeped in the luxury of ignorance concept.

Old prejudices came up, ideas of groups of 'Mexicans' being violent towards one white woman alone at night.... In the first class it was interesting feeling my tension creep in as the men in the group I was teaching 
in would talk in Spanish and laugh.... I began to realize, though, that we were all in a new space, probably somewhat uncomfortable, and that maybe they were just laughing because of that fact, not at me.

As the projects continued, students formed bonds with individuals they would not have had the opportunity to meet otherwise. Their sense of action and justice grew exponentially and the intersectionality of all the studies we had done were felt as real and not just theoretical. One student wrote, "In many ways, extending across the barrier of language is extending across barriers of class, race, and culture...essential information about and access to medical, legal, housing, education, and economic resources is primarily only available to English speakers."

Students who worked with local action groups had more of a tendency to lean toward a missionary zeal because they did not always have direct contact with the Latino population as the English tutors did. The direct contact and engagement provided students a tangible, social relationship with which to work, and that, along with their own self-exploration, proved to be an effective strategy for a greater understanding of race, power, and privilege. One student who did have the opportunity to work with an interfaith group working for the rights of immigrants, as well as face-to-face with individuals from the Latino community, made the important realization that,

"While the [interfaith] group has made connections across churches and faiths, I see that they do not have much contact with the Latino community. I think this is one of the most important pieces missing from [our] pro-immigrant contingents...they are not sharing each other's realities and fulfilling the ideals of interculturalism. This is why I am so passionate about having all of these people come together and so glad I could be a part of facilitating that."

\title{
"La Entrada"
}

One student titled her social action project paper, "La Entrada," or the entrance/entryway. In her analysis, she described how this course had been an entryway to exploring a way of being, to exploring a way of doing good work including exploring her privilege. I find her title compelling and would add to her description that the journey these students began in our tiny classroom was an entrance for their own identity analysis and an entryway to becoming culturally responsive, socially just educators. Through the action projects an entryway was opened for the day laborers who stand across the street from our college to be offered an invitation to learn English, free of judgment, free of threats or raids, and for our college students to enter into relationships they wouldn't normally have the opportunity to build. Because of these relationships, the critical self-analysis and the in-depth study of race, power, and privilege came alive for these students as did their deeper understanding of what it means to be a culturally responsive, socially just teacher:

\begin{abstract}
What can I do, as a human being-a human being with a growing sense of positive, white, heterosexual, woman identity-do to foster an equitable system and deconstruct the old dominance system? I feel like I am stepping out of the mire of shame and am empowered to do social justice work in a way that is genuine, productive, and sustainable. I also know that, whereas it might have been an option a few months ago, now I can never go back. Knowing what I know now, I no longer have the luxury of ignorance and I no longer can not do this work.
\end{abstract}

Borders are not always permeable or realistically removable, but borderlands, like the street that marks the division between our college and the migrant workers, can hopefully become a place "where the space between two individuals shrinks with intimacy" (Anzaldúa, p.19), and a place where we begin to look at how our actions, or lack thereof, impact individuals around us, even across the street. We are always on the borderlands and regardless of our geographical location, we have borderlands outside our front doors, and by using them as a teaching tool for future educators we can contribute to reconfiguring racial, ethnic, class, and linguistic borderlands that impact education and therefore, children.

\section{References}

Anzaldúa, G. (1999). Borderlands: La Frontera. San Francisco: Aunt Lute Books.

Cochran-Smith, M. (2004). Taking stock in 2004: Teacher education in dangerous times. Journal of Teacher Education, 55 (1), 3-7.

Freire, P. (1970). Pedagogy of the Oppressed. New York: Continuum. 
Gay, G. (2000). Culturally Responsive Teaching: Theory, Research and Practice. New York: Teachers College Press.

Helms, J. E., ed. (1990). Black and white racial identity: Theory, research and practice. Westport, CT: Greenwood Press.

Howard, G. (2006). You Can't Teach What You Don't Know: White Teachers, Multiracial Schools. New York: Teachers College Press.

Kingsolver, B. (2005). Hightide in Tucson. New York: Harper Collins.

Tatum, B. (1992). Talking about race, learning about racism: The application of racial identity theory in the classroom. Harvard Educational Review 